\title{
In the Field
}

\section{Navigating the Archives: A Student's Perspective}

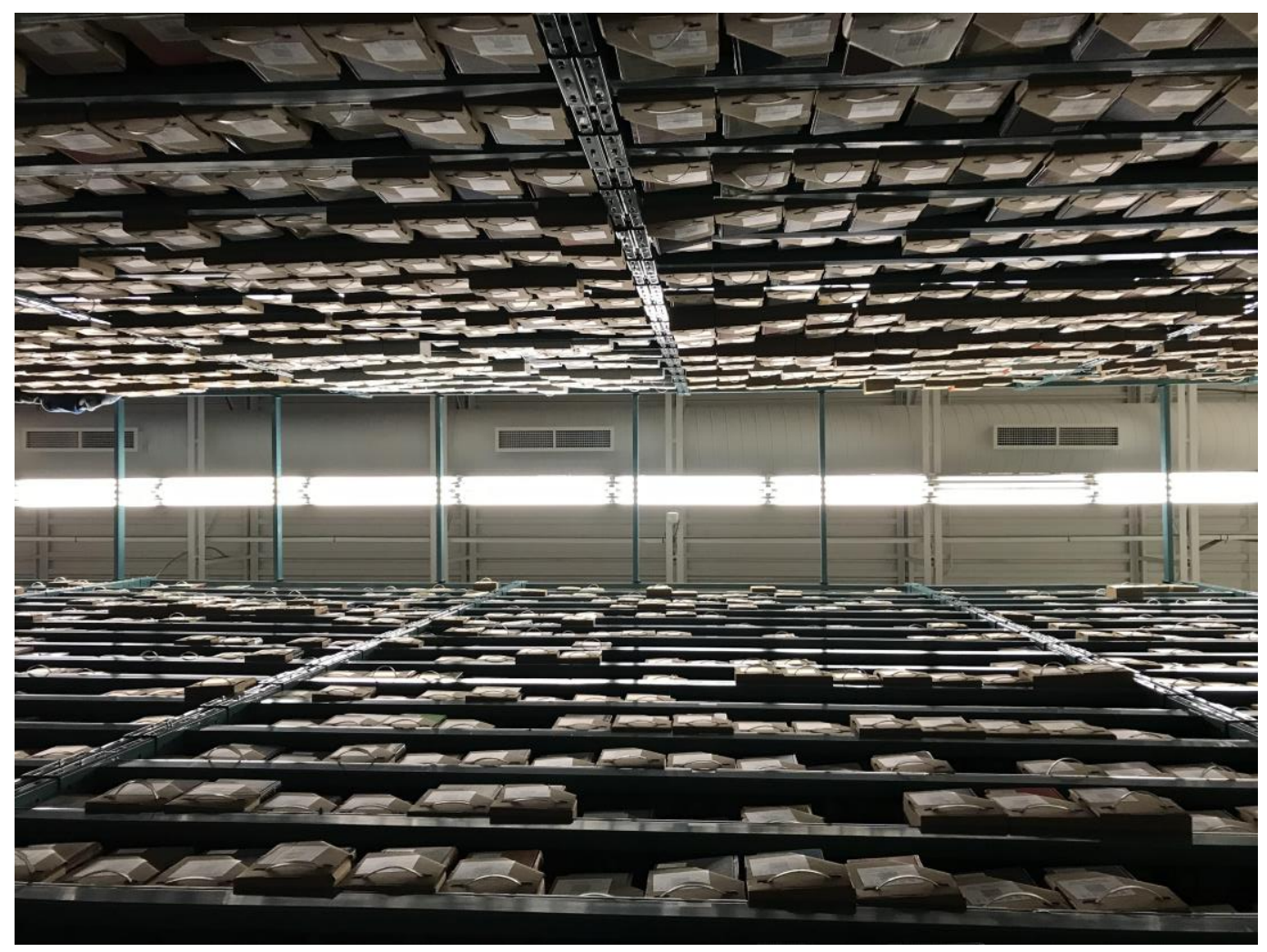

I served as the Co-op Student Archives Assistant at Western Libraries' Archives and

Special Collections Centre under the supervision of Robin Keirstead during the Summer and Fall terms in 2018. With little previous experience within archives, the main co-op project proved to be a complex collection that tested my limits as a student, professional, and researcher. At times, I felt pressure to create perfect work, but was eventually reminded that the work being done on this co-op would support the open and equal access to information and service. My experiences during this co-op placement allowed me to contextualize the theoretical knowledge taught in the classroom with real life situations and ultimately fostered both personal and professional growth. 
During my co-op I was tasked with imposing an intellectual order to a complex, artificial archival collection. Work done on this collection meant opening routes of access to students, researchers, and any interested individuals. This was done through the application of the archival processes of arrangement and description. The main project I worked on involved a complex collection that had been used for various purposes and had different classification systems, inventories, listings, and labelling applied to it. The collection was formed through various routes including multiple donations and purchases through auctions. Unfortunately, over time, the original order of the collection and the internal context of the records had been lost. Through collaboration with my supervisor, we were able to create a hierarchical intellectual order based on the creators of the collection.

Participation in the co-op program provided me with the opportunity to gain valuable practical experience. Throughout my placement I connected my co-op experiences to knowledge gained from Western's MLIS core content areas. This helped me contextualize theoretical concepts taught within the core content areas of Information Organization, Curation and Access, Connecting People with Information, and Managing and Working in Information Institutions.

Many opportunities arose to use the knowledge gained from the content areas of Information Organization and Curation and Access during my time at Western Archives. Through my hands-on experience in arrangement, description, and preservation practices with various archival media I contextualized how different information is organized for access and clarity. Considering the ways in which researchers search for and find relevant information helped me to construct a helpful finding aid. Working at 
Western's Archives and Special Collections also allowed me to observe how staff supported the acquisition, maintenance, organization, and access of their archival and special collection holdings.

Through reference, outreach, and engagement I not only observed, but also practiced Connecting People with Information. Engaging patrons in the reading room and attending community engagement events gave me the opportunity to interact with interested users of archival and special collection materials. Answering reference questions posed during online library reference chats allowed me to gain experience in conducting a digital reference interview and provided real-time experience in searching for relevant information to aid students, professors, and researchers. Mounting displays for exhibits and creating social media content helped me understand how archival institutions conduct community outreach and connect people with their content and holdings.

Additionally, I was given the unique opportunity to observe Managing and Working in Information Institutions within Western Libraries during my time as a co-op student. My supervisor encouraged me to attend institutional proceedings, like budget town halls and hiring presentations, which allowed me to contextualize some political and economic elements within the management of academic library institutions. Collaborating with different departments for events like the 100th Anniversary of the John Davis Barnett library donation allowed me to observe the efforts put into planning and implementing library-run events. Participating in Western Libraries' Annual Staff Session and connected with library professionals helped me to gain further insight into working within an information institution like Western's academic library. 
Apart from the project-specific experiences, my time at my co-op placement challenged the way I view myself as an information professional. As students, we are constantly faced with rigid deadlines, benchmarks, and goals. Personally, I find a strange comfort in grading matrices and knowing what exactly is expected from me as a student. Wrestling with the complex collection during my co-op placement tested my flexibility and adaptability. I learned that theory does not always transfer neatly within practice, and I learned a lot about myself as a student, individual, and future information professional. Through combatting imposter syndrome, doubt and fear would creep into my thoughts when faced with challenges. However, learning to understand both my own capabilities and limitations helped put things into perspective. In every experience, both good and bad, I was able to take something away from it. There is value in gaining perspective and knowledge through trial and error.

It was not until the last month of my co-op placement that I realized the work being done on this collection and during every co-op placement was bigger than myself, or any one individual. I was reminded of my goal as an information professional to advocate for the open and equal access to information and service. The work done during my co-op placement will aid in the future access to this beautiful, complex, and rich collection. My work will allow researchers, students, and interested individuals the opportunity to discover, learn, and explore its story. I feel very fortunate to have had my co-op experience in a place that fostered my learning, encouraged me to explore new areas of thought, and challenged my preconceived ideas of archival work. As information professionals, we should continue to push ourselves and wrestle with the issues our field faces to further contribute to the progress of information access. 


\section{Astrid Faith Ramos}

Ramos, A. F. (2019). Navigating the archives: a student's perspective. Emerging Library \& Information Perspectives, 2, 187-191. https://doi.org/10.5206/elip.v2i1.6207 